\title{
The Value of Treatment Processes in Germany: A Discrete Choice Experiment on Patient Preferences in Complementary and Conventional Medicine
}

\author{
Daniela Adam ${ }^{1} \mathbb{1} \cdot$ Theresa Keller $^{1} \cdot$ Axel Mühlbacher $^{2} \cdot$ Maximilian Hinse $^{1} \cdot$ Katja Icke $^{1} \cdot$ Michael Teut $^{1}$. \\ Benno Brinkhaus ${ }^{1} \cdot$ Thomas Reinhold $^{1}$
}

Published online: 19 December 2018

(c) The Author(s) 2018

\begin{abstract}
Background The effects of health interventions are often complex, and it is argued that they comprise more than pure changes in clinical parameters. Aspects of the treatment process, so-called 'benefits beyond health', are often overlooked in the evaluation of health interventions but can be of value to the patients.

Objectives The aim of this study was to assess patients' preferences and willingness to pay regarding the treatment process and its attributes in patients using acupuncture, homeopathy or general medicine (GM).

Methods A systematic literature search, six semi-structured interviews and a stakeholder involvement were conducted to determine the attributes of the treatment process. Five process attributes and one cost attribute were used to construct the experimental design of the discrete choice experiment (DCE) $(6 \times 3)$, a cross sectional survey method. Patients were recruited by outpatient physicians practicing in Berlin and Munich, Germany. Process attributes were effects-coded. Data were analyzed in a conditional logit regression.

Results Data from 263 patients were analyzed. DCE results showed that the treatment process attributes 'active listening' and 'time' were most relevant to all patients. Preferences for the attributes 'holistic treatment' (more relevant to the acupuncture and homeopathy groups) and 'information' (more relevant to the GM group) seemed to differ slightly between the groups. Willingness-to-pay values were higher in the acupuncture and homeopathy groups.

Conclusions The time physicians take and the extent to which they listen attentively are most important and are equally important to all patients. These results may contribute to the debate about more patient-centered healthcare. They support a strengthening of medical consultations in the German healthcare system. We suggest giving physicians the opportunity to spend more time with their patients, which may be achieved by changing the general conditions of remuneration (e.g., improved reimbursement of medical consultations).
\end{abstract}

German Clinical Trial Register DRKS00013160.

Benno Brinkhaus and Thomas Reinhold contributed equally.

Electronic supplementary material The online version of this article (https://doi.org/10.1007/s40271-018-0353-1) contains supplementary material, which is available to authorized users.

Daniela Adam

daniela.adam@charite.de

1 Institute for Social Medicine, Epidemiology and Health Economics, Charité - Universitätsmedizin Berlin, Corporate Member of Freie Universität Berlin, Humboldt-Universität zu Berlin, Luisenstr. 57, 10117 Berlin, Germany

2 Health Economics and Healthcare Management, Hochschule Neubrandenburg, Neubrandenburg, Germany 


\section{Key Points for Decision Makers}

The treatment process characteristics of time given by the physicians and the extent to which they attentively listen to the patient are most important and are equally important to patients using acupuncture, homeopathy or general medicine. These process characteristics should be taken into consideration in the debate about more patient-centered healthcare in Germany.

The willingness-to-pay results differed between the groups. Patients in the general medicine group were more cost sensitive than patients in the complementary and integrative medicine groups. The acupuncture and homeopathy patients may be used to out-of-pocket payments, as not all treatments are covered by statutory health insurances in Germany. However, the results have to be interpreted carefully as different patterns of willingness to pay might have existed within the groups.

\section{Introduction}

The effects of health interventions are often complex and multifaceted. Many researchers argue that the benefits of healthcare interventions comprise more than pure health outcomes such as changes in clinical parameters [1-4]. These authors claim that 'biopsychosocial' factors or the process of treatment lead to so called 'benefits beyond health', which potentially contribute to the patients' well-being and the overall treatment effect. Aspects of treatment like caring, respecting patients' dignity and autonomy, and providing information have value to the patient. "There are processes that patients go through to get to the outcomes. These processes are not always and not necessarily "utility neutral"'. [1]. Quality-adjusted life-years and other measures of health gains do not assess these process characteristics and their utilities [1]. They do not capture the full range of patients' benefits [5].

A more comprehensive concept of healthcare is often attributed to complementary and integrative medicine (CIM) [6] but is equally applicable to conventional medicine since all patients go through a treatment process [2]. It is necessary to consider these indirect health benefits in order to conduct comprehensive clinical and economic research for both $\mathrm{CIM}$ and conventional medicine, which in the end informs decision makers in healthcare [2].

CIM methods are frequently used in Germany. Acupuncture (34.5\%) and homeopathy (27.3\%) account for the majority of CIM usage [7]. Acupuncture has been successfully proven as effective for several indications [8]. Since 2007, it has been part of the catalogue of benefits offered by statutory health insurances for some of these medical indications [9]. Homeopathic treatments are partially reimbursed by selective contracts [10]. Nevertheless, homeopathy is critically discussed in science and society. The effectiveness of homeopathic treatments and the mode of action of highly diluted homeopathic medicines are unclear [11, 12]. For both treatment methods, the extent to which indirect health benefits may contribute to the overall treatment effect is not fully understood.

The goal of this study was to investigate indirect health benefits in CIM and conventional medicine. We examined relevant elements of the treatment process from the patients' perspective and the value they attach to them in outpatient, primary healthcare settings. A discrete choice experiment (DCE) was performed to assess patients' preferences and the utility resulting from the treatment process and its attributes. The secondary objective was to estimate the patients' willingness to pay for these attributes. Patients' preferences were evaluated for three types of treatment: acupuncture, homeopathy and general medicine (GM).

\section{Methods}

\subsection{Discrete Choice Experiments}

The DCE, a non-random, cross-sectional survey method, was used to assess patients' preferences and the related benefits (utilities). In DCEs, participants are presented with a sample of hypothetical scenarios (choice sets) describing the object of investigation (e.g., process of treatment) by several attributes (characteristics) and levels. Based on statistical design principles, choice sets are selected and arranged into choice tasks. Participants are asked to choose the preferred alternative in each choice task [13]. DCEs are based on Lancaster's [14] economic theory of value. Individuals' preferences are revealed by the choices they make and are summarized through their utility function. DCE results are then used to model the preferences within a random utility maximization framework [15].

\subsection{Development of the DCE Questionnaire}

A systematic literature search was conducted in June 2016 using Medline and Embase to identify any relevant literature on DCEs in CIM. Search terms for acupuncture and/or homeopathy were combined with those for conjoint analysis and willingness to pay. We identified one DCE publication on acupuncture [16] and one on homeopathy [17]. To develop a better understanding of the treatment processes, medical consultations in acupuncture and homeopathy were observed by a member of the research group. Additionally, 
ten outpatient physicians known by our institution were asked via email to name the characteristics of the treatment process and what they believed to be important for their patients. Six semi-structured interviews were conducted with patients who used acupuncture, homeopathy or GM. Patients were asked what had been most relevant for them regarding the treatment process. The received information regarding the process attributes of the previously listed steps was summarized and arranged for the stakeholder involvement. Participants of the stakeholder involvement (three patients, three physicians and three scientists) were asked to evaluate these process attributes regarding their importance and name others if necessary. Nine process attributes were identified altogether: active listening, time, holistic treatment, information, active participation, experience of the physician, technical equipment of the doctor's practice, structural elements (e.g., waiting time, rooms), and nonverbal communication (e.g., physical contact). The significance and importance of all process attributes were discussed. The stakeholder involvement was audio recorded and a protocol was written. The attributes shown in Table 1 were found to be essential to the participants of the stakeholder involvement and were therefore chosen to be part of the DCE. Process attributes' levels were chosen according to the Likert-Type Scale Response Anchors [18]. Levels for the cost attribute were based on a selective contract for outpatient homeopathy [19] and the doctors' fee scale for outpatient services within the statutory health insurance ('Einheitlicher Bewertungsmaßstab') for GM and acupuncture [20].

SAS version 9.4 (SAS Institute, Cary, NC, USA) was used to create an experimental design out of 729 possible choice sets $\left(3^{6} ;\right.$ six attributes, three levels) [21]. The choice design consisted of 18 choice sets arranged into six choice tasks, each containing three alternatives (forced choice). Figure 1 shows an example of a choice task. The relative D-efficiency of the experimental design was $100 \%$; i.e., the design can be considered balanced and orthogonal [22].

The questionnaire contained one choice task with a dominated alternative. It was used to assess patients' understanding of the attributes and levels. The dominated alternative was described by logically less preferable levels across all attributes. If it was chosen by the patients, they were defined as 'irrational' and were excluded from the analyses.

To describe our study population, the questionnaire contained additional questions on sociodemographic characteristics (age, sex and education), health complaints and the condition of the disease being treated (acute or chronic). Moreover, patients were asked to state if they have used acupuncture, homeopathy or GM simultaneously in order to assess the overlap in the treatment groups.

The first version of the questionnaire was pretested $(n=25)$ and adapted accordingly. The sample size was calculated according to Orme [23].

$\frac{n \times t \times a}{c} \geq 500$

where $n$ is the number of respondents, $t$ is the number of tasks, $a$ is number of alternatives per task, and $c$ is the number of analysis cells (when considering main effects, $c$ is equal to the largest number of levels for any one attribute). For our choice design, $t=6, a=3, c=3$, which resulted in a minimum of 84 patients per group.

The study was approved by the ethics review board of the Charité-University Hospital Berlin (EA1/320/16)

Table 1 Attributes: descriptions and corresponding levels

\begin{tabular}{|c|c|}
\hline Attributes & Levels \\
\hline $\begin{array}{l}\text { Active listening } \\
\text { The doctor-patient relationship is characterized by attention and active listening. The doctor is empathetic and responds to you } \\
\text { and your situation }\end{array}$ & $\begin{array}{l}\text { Rarely } \\
\text { Sometimes } \\
\text { Often }\end{array}$ \\
\hline $\begin{array}{l}\text { Time } \\
\text { During the treatment you have the opportunity to explain your health situation or problems calmly. The doctor makes sufficient } \\
\text { time for you and your treatment }\end{array}$ & $\begin{array}{l}\text { Rarely } \\
\text { Sometimes } \\
\text { Often }\end{array}$ \\
\hline $\begin{array}{l}\text { Holistic treatment } \\
\text { During the treatment there is enough space to discuss all health-related levels (e.g., physical, mental, emotional, social). Connec- } \\
\text { tions between the levels become clear. In addition, your entire medical history is examined }\end{array}$ & $\begin{array}{l}\text { Rarely } \\
\text { Sometimes } \\
\text { Often }\end{array}$ \\
\hline $\begin{array}{l}\text { Information } \\
\text { The physician provides extensive and comprehensible information on diagnosis and therapy. In addition, you receive recommenda- } \\
\text { tions on lifestyle changes (e.g., diet, exercise, relaxation) }\end{array}$ & $\begin{array}{l}\text { Rarely } \\
\text { Sometimes } \\
\text { Often }\end{array}$ \\
\hline $\begin{array}{l}\text { Active participation of the patient } \\
\text { The treatment promotes your understanding, perception and the sense of responsibility for yourself and your illness. You acquire } \\
\text { the ability to actively participate in the healing process }\end{array}$ & $\begin{array}{l}\text { Rarely } \\
\text { Sometimes } \\
\text { Often }\end{array}$ \\
\hline $\begin{array}{l}\text { Additional costs per treatment } \\
\text { Amount you would have to pay for a session of the described treatment in addition to your regular health insurance contributions }\end{array}$ & $\begin{array}{l}€ 0 \\
€ 30 \\
€ 60\end{array}$ \\
\hline
\end{tabular}




\begin{tabular}{|c|c|c|c|}
\hline Characteristics of the treatment process & $\begin{array}{l}\text { treatment } \\
\text { process } \mathrm{A}\end{array}$ & $\begin{array}{l}\text { treatment } \\
\text { process B }\end{array}$ & $\begin{array}{l}\text { treatment } \\
\text { process C }\end{array}$ \\
\hline $\begin{array}{l}\text { Active listening } \\
\text { The doctor listens to me actively and } \\
\text { attentively. }\end{array}$ & sometimes & often & rarely \\
\hline $\begin{array}{l}\text { Time } \\
\text { The doctor makes enough time for me and } \\
\text { the treatment. }\end{array}$ & often & sometimes & rarely \\
\hline $\begin{array}{l}\text { Holistic treatment } \\
\text { All levels of my health (e. g. physical, } \\
\text { mental, emotional, social) are considered } \\
\text { coherently. }\end{array}$ & often & often & rarely \\
\hline $\begin{array}{l}\text { Information } \\
\text { I receive sufficient and understandable } \\
\text { information on diagnosis and therapy as } \\
\text { well as recommendations on lifestyle. }\end{array}$ & rarely & sometimes & often \\
\hline $\begin{array}{l}\text { Active participation of the patient } \\
\text { I have the feeling of playing an active role } \\
\text { in the healing process. }\end{array}$ & sometimes & rarely & sometimes \\
\hline Additional costs per treatment & $30 €$ & $60 €$ & $0 €$ \\
\hline $\begin{array}{l}\text { I would choose... } \\
\text { (please check only one option) }\end{array}$ & $\begin{array}{l}\text {...treatment } \\
\text { process A }\end{array}$ & $\begin{array}{c}\text {...treatment } \\
\text { process B }\end{array}$ & $\begin{array}{c}\text {...treatment } \\
\text { process C }\end{array}$ \\
\hline
\end{tabular}

Fig. 1 Example of a choice task

and was registered in the German Clinical Trial Register (DRKS00013160).

\subsection{Data Collection and Study Population}

Outpatient physicians practicing in Berlin and Munich, Germany, were contacted by email, letter and telephone through the register of the Regional Association of Social Health Insurance-accredited Physicians ('Kassenärztliche Vereinigung') and through a list of physicians known by our institution. Physicians were either practicing GM exclusively or had an additional qualification in acupuncture or homeopathy and treated patients with statutory or private health insurance. All participating physicians were informed about the study aim and were asked to distribute the questionnaires to their patients. DCE questions were equal for all patients. The questionnaire was provided online or as a hardcopy. A brochure containing all relevant information about the study was handed out to the patients. Participation was voluntary and anonymous and could be cancelled at any time. According to the physician's treatment approach, patients were labeled as acupuncture, homeopathy or GM patients.

The following inclusion criteria applied: the patients must be at least 18 years of age and must be undergoing treatment from a participating acupuncturist, homeopath or GM physician. An exclusion criterion was insufficient German language skills.

\subsection{Statistical Model and Data Analysis}

A conditional logit regression [15] was performed to analyze patients' preferences regarding the treatment process. In a conditional logit, the probability of choice among the alternatives is related to the attribute levels characterizing the alternatives [24]. SAS was used to estimate the coefficients (preference weights) and the standard errors (SE) 
for all attribute levels. All process attributes were analyzed as categorical variables, and effects coding (reference category is coded -1) was used. The cost attribute was coded and analyzed as a linear continuous variable. The regression model was run separately for all three study groups. The robust sandwich estimates of Lin and Wei [25] were used to assess the variance covariance matrix.

Descriptive analysis of the patient characteristics was performed by PASW statistics version 22.0.0.1 (SPSS Inc, Chicago, IL, USA). Figures were plotted using RStudio version 1.1.383 (RStudio, Inc., Boston, MA, USA) and the package ggplot2 [26].

\subsection{Interpretation of Regression Results}

There are different ways to interpret the results of the regression. The span of the estimated preference weights from one attribute level to the next level of the same attribute reflects the relative importance of that level change; i.e., the longer the distance is, the more important the change (e.g., moving from 'rarely' active listening to 'sometimes' active listening) [27]. It shows the gain or loss in utility $(U \Delta)$ for the patients resulting from the change in attribute levels [28].

Trade-offs are another way to look at the results. The magnitude of differences in preference weights or utility can be compared across attributes. One specific trade-off is calculated by the ratio between preference weights of process and cost attributes (willingness to pay) [24].

The 'raw' coefficients cannot be directly compared between the groups. They are only comparable within one model or rather within one group [24]. The attributes can be compared within one group and across groups by calculating the relative importance of each attribute. Therefore, the difference in preference weights of the most and least preferred levels of one attribute is compared with preference weight differences of the other attributes. The level difference of each attribute is then normalized on a 10-point scale (normalized level difference). Ten points reflect the biggest level difference and the most important attribute [27]. Still, confidence intervals for the normalized level difference of the attributes are only meaningful within one group and are not comparable across the others.

\section{Results}

\subsection{Patients' Characteristics}

Patients were recruited by 34 physicians (14 acupuncturists, 9 homeopaths and 11 GM physicians) between January and September 2017. In total, questionnaires were distributed to 608 patients, of whom 285 participated in the survey. The response rate was $47 \%$. A total of 22 questionnaires had to be excluded from the analyses: four patients did not meet the inclusion criteria, 13 did not complete the DCE, and five were defined as 'irrational' responses. The 'irrational' responses were given by patients from the GM group. These respondents were mostly male ( 3 men, 1 woman, and 1 'not stated'), with a mean age of 48.8 years (SD 16.8) and a mean duration of education of 11.6 years (SD 1.1). Three of these patients reported having a chronic condition.

Altogether, 263 questionnaires were included in the analyses (acupuncture 91, homeopathy 87, and GM 85). With 18 choice sets per subject, the data contained 4734 observations (acupuncture 1638, homeopathy 1566, and GM 1530).

Table 2 shows the characteristics of the participating patients. All groups contained more women than men, with the largest portion of women in the CIM groups (acupuncture and homeopathy). Patients in the GM group were older, and mean duration of education was longest in the CIM groups. In the acupuncture group, patients were being treated mainly for musculoskeletal disorders and mental illnesses. Almost one-third of the homeopathy patients visited their physician because of mental illnesses. GM patients mostly reported complaints due to cardiovascular diseases. The category 'other diseases' included, among others, atopic dermatitis, and rheumatic and autoimmune diseases. More patients in the CIM groups experienced chronic conditions than in the GM group. Almost half of the acupuncture group visited a GM physician at the same time due to either the stated diseases or other conditions. In contrast, there was hardly any overlap in the GM group, and only $5.9 \%$ of the GM patients simultaneously visited an acupuncturist.

\subsection{Preference Weights}

Results of the conditional logit regression models are presented in Table 3. Coefficient signs indicate whether the attribute levels lead to an increase (positive) or a decrease (negative) in patients' utility. $p$ values represent the statistical difference between the preference weight of the attribute levels and the mean effect of the same attribute [24]. Model fit values are displayed at the bottom of the table. Figure 2 illustrates the preference weights with $95 \%$ confidence intervals (CIs) for all study groups. To simplify the illustration of the results, we decided to present all preference weights in one graph, although the 'raw' coefficients are not comparable between the groups. In the following sections, the regression results shown in Table 3 and Fig. 2 are interpreted for each study group.

\subsubsection{Acupuncture}

The most important level changes for the acupuncture group were related to the attribute 'active listening' $\left(U \Delta_{\text {Listen }}+\right.$ $1.24)$, followed by 'time' $\left(U \Delta_{\text {Time }}+1.13\right)$ and 'holistic 
Table 2 Patient characteristics

\begin{tabular}{|c|c|c|c|c|}
\hline Sociodemographic characteristics & Acupuncture $(N=91)$ & Homeopathy $(N=87)$ & $\begin{array}{l}\text { General medicine } \\
(N=85)\end{array}$ & Total $(N=263)$ \\
\hline \multicolumn{5}{|l|}{$\operatorname{Sex}, \%(n)$} \\
\hline Male & $27.8(25)$ & $24.1(21)$ & $31.7(26)$ & $27.8(72)$ \\
\hline Female & $72.2(65)$ & $75.9(66)$ & $67.1(55)$ & $71.8(186)$ \\
\hline Other & $0(0)$ & $0(0)$ & $1(1)$ & $0.4(1)$ \\
\hline Age $[y]$, mean $\pm S D$ & $51.8 \pm 13.7$ & $54.3 \pm 12.4$ & $57.0 \pm 18.4$ & $54.3 \pm 15.1$ \\
\hline Duration of education $[y]$, mean \pm SD & $17.6 \pm 3.2$ & $18.4 \pm 4.2$ & $14.5 \pm 3.4$ & $16.9 \pm 4$ \\
\hline \multicolumn{5}{|l|}{ Health complaints, $\%(n)$} \\
\hline Cardiovascular disease & $3.3(3)$ & $8.0(7)$ & $30.6(26)$ & $13.7(36)$ \\
\hline Respiratory disease & $7.7(7)$ & $13.8(12)$ & $15.3(13)$ & $12.2(32)$ \\
\hline Mental illness & $19.8(18)$ & $32.2(28)$ & $9.4(8)$ & $20.5(54)$ \\
\hline Musculoskeletal disorder & $29.7(27)$ & $19.5(17)$ & $22.4(19)$ & $24.0(63)$ \\
\hline Metabolic disease & $2.2(2)$ & $2.3(2)$ & $20.0(17)$ & $8.0(21)$ \\
\hline Gastrointestinal disease & $9.9(9)$ & $13.8(12)$ & $14.1(12)$ & $12.5(33)$ \\
\hline Cancerous disease & $1.1(1)$ & $4.6(4)$ & $4.7(4)$ & $3.4(9)$ \\
\hline Ear-nose-throat disease & $13.2(12)$ & $16.1(14)$ & $4.7(4)$ & $11.4(30)$ \\
\hline Pain condition & $6.6(6)$ & $5.7(5)$ & $1.2(1)$ & $4.6(12)$ \\
\hline Neurological disease & $5.5(5)$ & $4.6(4)$ & $1.2(1)$ & $3.8(10)$ \\
\hline Other diseases & $16.5(15)$ & $18.4(16)$ & $2.4(2)$ & $12.5(33)$ \\
\hline \multicolumn{5}{|l|}{ Status of disease, $\%(n)$} \\
\hline Acute & $24.2(22)$ & $13.8(12)$ & $18.8(16)$ & $19.0(50)$ \\
\hline Chronic & $69.2(63)$ & $70.1(61)$ & $63.5(54)$ & $67.7(178)$ \\
\hline Not sure & $7.7(7)$ & $17.2(15)$ & $15.3(13)$ & $13.3(35)$ \\
\hline \multicolumn{5}{|l|}{ Treatment group overlap, $\%(n)$} \\
\hline Acupuncture & & $14.3(13)$ & $46.2(42)$ & $(55)$ \\
\hline Homeopathy & $8.0(7)$ & & $28.7(25)$ & $(32)$ \\
\hline General medicine & $5.9(5)$ & $0(0)$ & & (5) \\
\hline
\end{tabular}

$S D$ standard deviation

treatment' $\left(U \Delta_{\text {Holistic }}+1.07\right)$, moving from 'rarely' fulfilled to 'sometimes' fulfilled. These level changes resulted in the largest utility gain for the patients. Differences in preference weights for an increase in time taken by the doctor and a more holistic treatment approach were similar (both moving from 'sometimes' to 'often'; $U \Delta_{\text {Time }}+0.57, U \Delta_{\text {Holistic }}$ $+0.56)$. Regarding willingness to pay, the level change in active listening from 'rarely' fulfilled to 'often' fulfilled $\left(U \Delta_{\text {Listen }}+1.94\right)$ had a monetary value of $€ 252.51$.

\subsubsection{Homeopathy}

Patients of the homeopathy group valued the level change from 'rarely' to 'sometimes' regarding the time taken by the doctor as most important $\left(U \Delta_{\text {Time }}+1.42\right)$. Level changes from 'sometimes' to 'often' in the attributes of active listening and information were equally important to the homeopathy patients $\left(U \Delta_{\text {Time }}+0.69, U \Delta_{\text {Info }}+0.68\right)$. Willingnessto-pay estimates for the level change in time from 'rarely' fulfilled to 'often' fulfilled $\left(U \Delta_{\text {Time }}+1.92\right)$ resulted in a monetary value of $€ 147.58$.

\subsubsection{General Medicine}

For the GM patients, the level change from 'rarely' to 'sometimes' in the attributes 'active listening' and 'time' were valued as most important and equally important $\left(U \Delta_{\text {Listen }}\right.$ $\left.+0.74, U \Delta_{\text {Time }}+0.68\right)$. Looking at willingness to pay, the level change in active listening from 'rarely' fulfilled to 'often' fulfilled $\left(U \Delta_{\text {Listen }}+1.15\right)$ had a monetary value of $€ 96.40$ for the patients of the GM group.

\subsubsection{Group Comparison}

Figure 3 shows the relative importance of each attribute with 95\% CIs. Active listening and time were the two most relevant attributes for the patients of all groups, whereas the attribute 'active participation' was least important. For the CIM patients, the attribute 'holistic treatment' seemed to be 


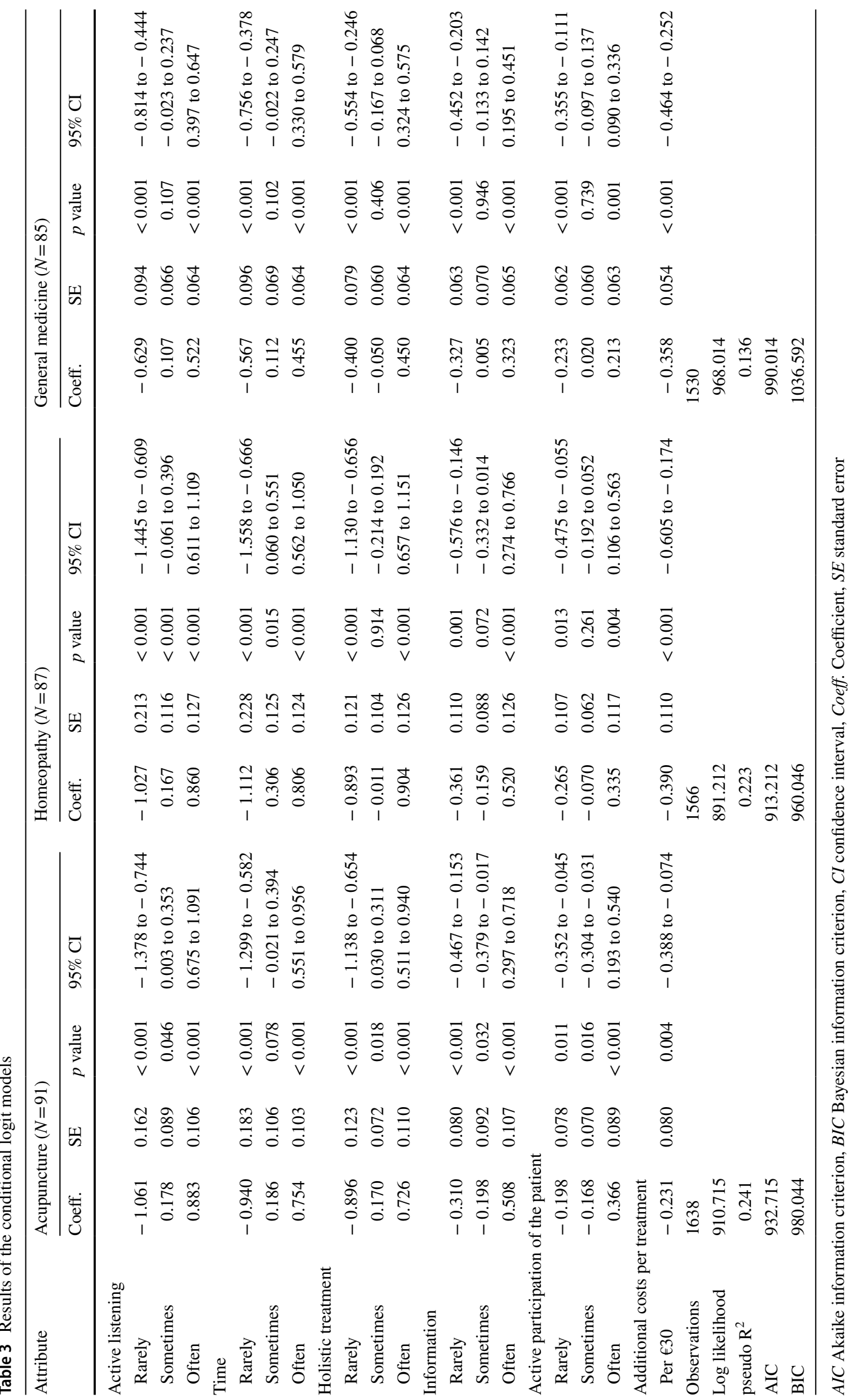




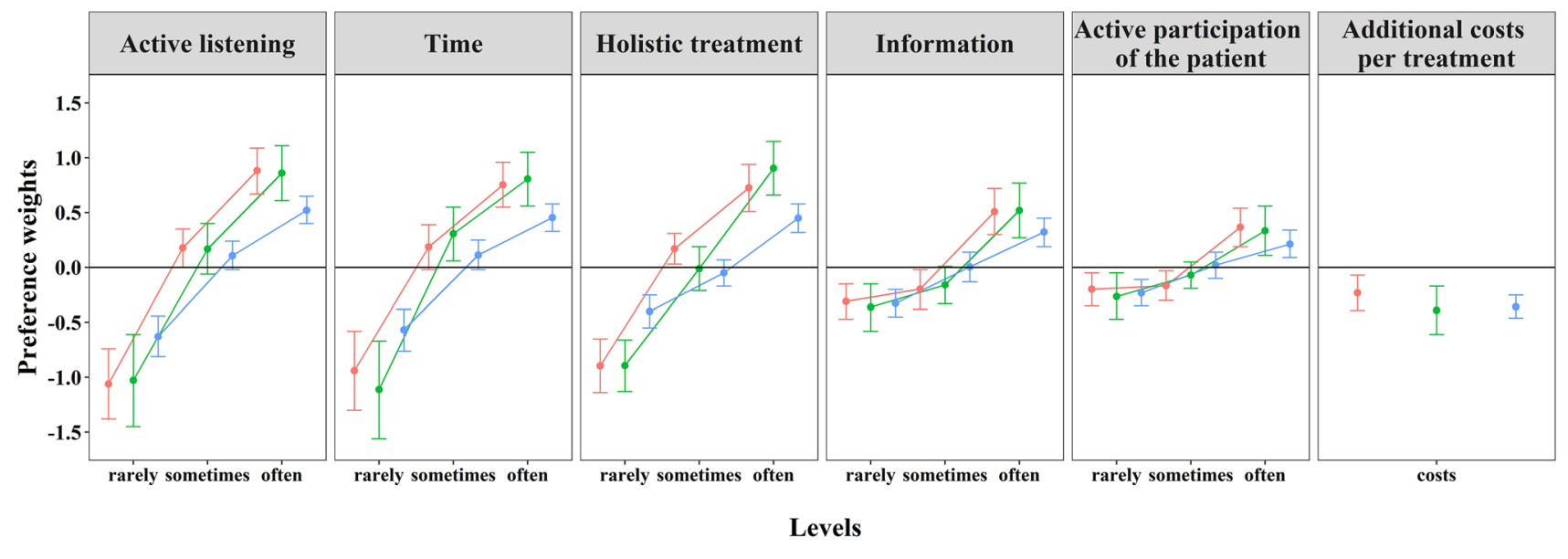

Groups $\rightarrow$ Acupuncture $\rightarrow$ Homeopathy $\rightarrow$ General Medicine

Fig. 2 Results of the conditional logit model

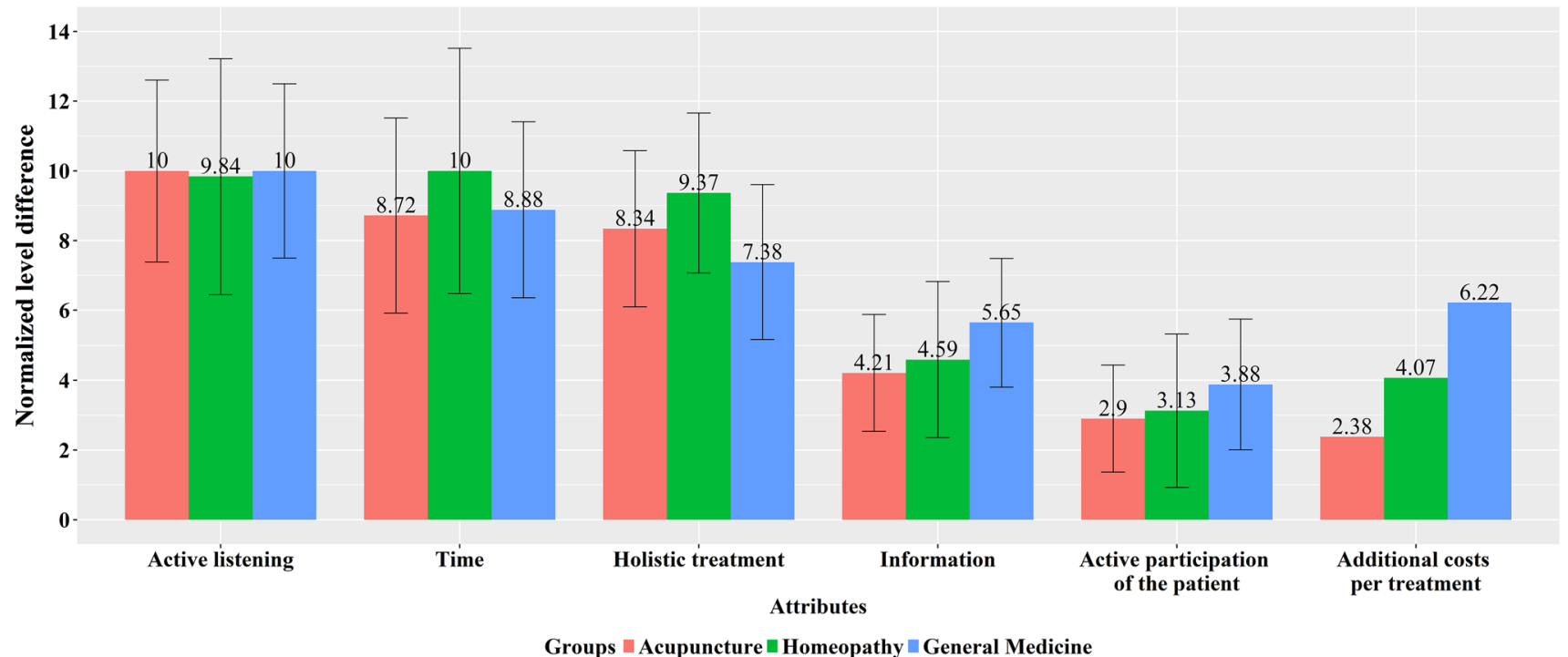

Fig. 3 Relative importance of attributes

slightly more relevant. The information provided by the physician appeared to be more important to the patients of the GM group. Comparing the results of the cost attribute, it was most important to the GM patients and least important to the acupuncture patients. For more details, see Appendix Table 1 in the Electronic Supplementary Material.

\section{Discussion}

\subsection{Interpretation of the Discrete Choice Experiment Results}

The patients of all study groups valued active listening and time as the two most important attributes of the treatment process. These findings may help in understanding the indirect health benefits of the investigated treatment settings. In Western countries, CIM physicians take on average more time for the consultation and the assessment of medical history, as it is often an inherent part of the therapy [29]; for example, diagnostics according to Chinese medicine in acupuncture or comprehensive anamnesis in homeopathy. Considering our results, this may contribute to the effectiveness of acupuncture and homeopathy, as patients gain more value from the treatment process. In contrast with CIM therapies, GM consultations are often shorter in time, and physicians have a higher workload. In general, they see more patients in the same time period than CIM physicians [29]. Potential differences between the groups were seen 
in the attributes 'holistic treatment', which appeared to be slightly more relevant to acupuncture and homeopathy patients, and 'information', which seemed to be more important to the GM patients. These group differences may be explained by a different understanding of health and disease, referred to as salutogenesis [30] in CIM and pathogenesis in conventional medicine, but this is only a hypothesis and should be investigated in future research.

Regarding willingness to pay, patients in the GM group attached greater importance to the cost attribute than patients in the CIM groups. A possible explanation could be that patients in the CIM groups are less cost sensitive because they are used to out-of-pocket payments, as not all acupuncture and homeopathy treatments are covered by the catalogue of benefits from statutory health insurances $[9,10]$. Nevertheless, the willingness-to-pay results have to be interpreted carefully. Different patterns of preferences regarding the cost attribute might have existed within the groups. As mentioned above, patients in the acupuncture or homeopathy groups might have used different methods of payment, which can influence their willingness to pay. Unfortunately, we could not investigate these potential patterns, as the number of patients in the groups was too small to conduct further analyses, such as a random parameter logit or a latent class analysis [24]. In addition, potential effects of recoding [31] cannot be ruled out. Recoding is a cognitive strategy used by the patients to simplify the evaluation of the cost attribute. Patients are often not used to direct payments for healthcare because costs are either fully or partially covered by their health insurance. Therefore, levels of the cost attribute may have been recoded into categories (e.g., 'low', 'medium', and 'high'), which can lead to distorted willingness-to-pay results [31].

\subsection{Strength and Limitations}

As far as we know, our study is the first to investigate process utility from a general perspective by comparing the settings of conventional and complementary medicine and considering willingness to pay at the same time.

Nevertheless, our study has several limitations. Concerning DCEs in general, it is questionable to what extent the study results represent real-world decisions. Patients choose between hypothetical treatment processes. Real-world decisions of respondents may consider other medical, financial or emotional consequences [27, 32]. We tried to minimize these potential differences by using qualitative methods, as described in the method section, to identify and select the attributes. Another restraint is that DCEs become more complex as the number of attributes and levels rises. The information patients can process is limited. To prevent the use of heuristics [33], researchers have to limit the number of attributes to meet methodical and cognitive requirements $[34,35]$. As a consequence, we excluded several attributes in the development stage of the questionnaire. Nonetheless, these attributes can be meaningful to patients and should be mentioned here again: experience of the physician, technical equipment, structural elements (waiting time, rooms, etc.), and nonverbal communication such as physical contact.

Looking at our study in particular, the greatest limitation is the high level of complexity of our choice design comprising three alternatives and six attributes per choice task. Patients are more likely to make use of heuristics to simplify the decision scenarios as the complexity of the choice design rises [36]. Latent class analysis can help to control for these heuristics but would need a higher number of respondents in each group to be conducted [33,37]. Additionally, potential interactions between the attributes have not been considered. The estimation of interaction effects needs a higher number of respondents. Future studies should take interaction effects into consideration. In particular, the attributes 'active listing' and 'time' are potentially correlated. Furthermore, generalizing the study results to the overall population of Germany is limited because the recruitment was restricted to urban areas. Heterogeneity between the patients from Berlin and Munich is possible (e.g., due to differences in the social structure of the local population) but likely to be small, as both are urban regions. Another limitation is the overlap in the study groups. Patients in the CIM groups (acupuncture $46 \%$ and homeopathy $29 \%$ ) visited GM physicians at the same time. As acupuncture and homeopathy are often used as complementary therapies, it was not possible to separate the groups neatly. However, most results of the sociodemographic characteristics in the CIM groups matched with latest results from the European Social Survey [38].

Another potential limitation of our study is the removal of data from five patients because they were defined as 'irrational'. Deleting responses from a DCE is discussed critically in the literature [39-41]. There are several reasons why this may not be appropriate [39]. Regarding our study, we made the assumption that all attribute levels of the dominated alternative were worse than the attribute levels of another alternative in the same choice task. However, this is only valid if patients prefer a greater fulfilment of the process attributes and lower values in the cost attribute. All process attributes are qualitative attributes. This means that the ordering of the levels can be unclear; for example, is it always better for the patients to participate actively in the treatment process, or do they maybe prefer a more passive role? A greater fulfilment of the process attributes is not necessarily preferred by all patients. Even higher costs can be attributed to a higher quality of care and hence be preferable [39]. Nevertheless, we decided to exclude the patients' data from our data set because the results for the GM group changed heavily and the model fit criteria worsened 
noticeably when including the data in our analyses (for more details, see Appendix Table 2 and Fig. 1 in the Electronic Supplementary Material). Moreover, an unclear ordering of attribute levels would be contrary to the results of the qualitative stage of this study.

Process utility is an intangible concept and therefore can be difficult to describe in a few attributes as well as to convey on an emotional and cognitive level. We suggest that upcoming studies should choose a more sophisticated choice design to avoid complexity of the choice tasks; for example, a blocked design with a larger sample size, more concise labels for the attribute levels, or a more appealing graphical representation of the attribute levels in the questionnaire, and that they should focus on a specific disease.

\subsection{Comparison with the Existing Literature}

There is a limited number of studies with comparable results. DCEs analyzing patients' preferences of treatment processes usually focus on a specific disease intervention, sometimes comprising clinical outcomes as well [17, 42-44]. In contrast, our study analyzed different settings of therapies-acupuncture, homeopathy and GM - and assessed process utility from a more general perspective. To our knowledge, only one study analyzed patients' preferences of the treatment process comparing a conventional setting with a complementary one. Ratcliffe [17] investigated the preferences of patients with asthma either receiving an outpatient conventional treatment or a homeopathic one. The results showed that the most important attributes for all patients were the 'time given by the doctor to listen to what the patient has to say', 'symptom relief' and 'travel costs for a consultation'. Only the homeopathic patients valued the attribute "be treated as a whole person" as important. To some extent, the results are comparable to ours. Our attributes 'active listening' and 'time' were represented by a single attribute in the Ratcliffe study [17], which patients also valued to be most important to them. Our attribute 'holistic treatment' was important to the GM patients as well but seemed to be more important to the patients of the homeopathy and acupuncture groups. 'Symptom relief' and 'travel costs' were not included in our attributes, and willingness to pay was not estimated by Ratcliffe [17].

A recent systematic review from Bien et al. [44] investigated patients' preferences for cancer treatment, classifying attributes into outcome, process and cost attributes. Results showed that outcome attributes were most relevant to patients. Process and cost attributes were less often included in DCE studies but were still of importance to the patients. Bien et al. [44] concluded that clinicians and decision makers should be aware that not only outcome attributes but also process and cost attributes have value to patients. This shows that more research on process and cost attributes is needed to capture the full range of patients' benefits.

\section{Conclusion}

The time physicians take for the consultation and the extent to which they attentively listen plays a major role for patients using acupuncture, homeopathy or GM. This should be taken into consideration within the discussion on providing more patient-centered care in Germany. Our results would support considering a change in the healthcare system towards a strengthening of medical consultations. We suggest giving physicians the opportunity to spend more time with their patients, which may be achieved by changing the general conditions of remuneration (e.g., an improved reimbursement of medical consultations).

Data Availability Statement The dataset generated and analyzed during the current study is available in the figshare.com repository: https://figshare.com/s/2413f41ef5 $6 \mathrm{ca} 08 \mathrm{cc} 040$.

Acknowledgements We would like to thank the participating patients, physicians and staff involved in the study. Moreover, we gratefully acknowledge the statistical support in data analysis from Andrew Sadler, M.Sc., as well as Martin Kittel, MD, and Barbara Stöckigt, MD, for their assistance in conducting the study. Additionally, we want to express our gratitude to the Karl und Veronica Carstens-Stiftung for the financial support of this study.

Author Contributions DA conceived and designed the discrete choice experiment with support from TR, BB and MT, analyzed and interpreted the data, and wrote the first draft of the manuscript. AM, TK and $\mathrm{MH}$ provided statistical support in data analysis. KI addressed the quality assurance of data entry and data safety. All authors were involved in the critical revision of the manuscript and approved the final version.

\section{Compliance with Ethical Standards}

Funding This study was partially supported by a grant from Karl und Veronica Carstens-Stiftung (grant KVC 01085/2016). DA reports a scholarship from the Charité-University Hospital Berlin for conducting the study.

Conflicts of interest BB, MT and DA received travel expenses, accommodation and free symposium registration by Karl und Veronica Carstens-Stiftung. BB and MT received research grants, personal fees and non-financial support from acupunctural and homeopathic organizations outside the submitted work. TK, AM, MH, KI and TR declare that they have no conflict of interest. The authors preclude any influence by the sponsor or other organizations on the choice of sample, the economic methods used and the study results.

Informed consent The study was approved by the ethics review board of the Charité-University Hospital Berlin (EA1/320/16). Written informed consent by the patients was redundant as no intervention 
was provided and participation was anonymous. However, a brochure containing all relevant information about the study was handed out to the patients.

Ethical approval All procedures performed in studies involving human participants were in accordance with the ethical standards of the institutional and/or national research committee and with the 1964 Helsinki declaration and its later amendments or comparable ethical standards.

Open Access This article is distributed under the terms of the Creative Commons Attribution-NonCommercial 4.0 International License (http://creativecommons.org/licenses/by-nc/4.0/), which permits any noncommercial use, distribution, and reproduction in any medium, provided you give appropriate credit to the original author(s) and the source, provide a link to the Creative Commons license, and indicate if changes were made.

\section{References}

1. Mooney G. Beyond health outcomes: the benefits of health care. Health Care Anal. 1998;6:99-105. https://doi.org/10.1007/BF026 78115.

2. Meenan R. Developing appropriate measures of the benefits of complementary and alternative medicine. J Health Serv Res Policy. 2001;6:38-43.

3. Cherkin DC. Primary care research on low back pain. The state of the science. Spine. 1998;23:1997-2002.

4. Evans RG, Stoddart GL. Producing health, consuming health care. Soc Sci Med. 1990;31:1347-63. https://doi.org/10.1016/02779536(90)90074-3.

5. Hollinghurst S, Shaw A, Thompson EA. Capturing the value of complementary and alternative medicine: including patient preferences in economic evaluation. Complement Ther Med. 2008;16:47-51. https://doi.org/10.1016/j.ctim.2007.10.001.

6. Vincent C, Furnham A. Why do patients turn to complementary medicine? An empirical study. Br J Clin Psychol. 1996;35:37-48.

7. Bücker B, Groenewold M, Schoefer Y, Schäfer T. The use of complementary alternative medicine (CAM) in 1001 German adults: results of a population-based telephone survey. Gesundheitswesen. 2008;70:e29-36. https://doi.org/10.1055/s-2008-1081505.

8. Vickers AJ, Cronin AM, Maschino AC, Lewith G, MacPherson H, Foster NE, et al. Acupuncture for chronic pain: individual patient data meta-analysis. Arch Intern Med. 2012;172:1444-53. https:// doi.org/10.1001/archinternmed.2012.3654.

9. Bundesausschuss Gemeinsamer. Bekanntmachung eines Beschlusses des Gemeinsamen Bundesausschusses über eine Änderung der Richtlinie Methoden vertragsärztliche Versorgung in Anlage I „Anerkannte Untersuchungs- oder Behandlungsmethoden"und in Anlage II „Methoden, die nicht als vertragsärztliche Leistungen zu Lasten der Krankenkassen erbracht werden dürfen“: Akupunktur. Bundesanzeiger. 2006;214:6952.

10. Managementgesellschaft des Deutschen Zentralvereins homöopathischer Ärzte mbH. Teilnehmende Gesetzliche Krankenkassen. Managementgesellschaft des DZVhÄ. 2017. https://www.manag ementgesellschaft-dzvhae.de/mmg-vertragsteilnehmer/krankenkas sen/. Accessed 25 Oct 2017.

11. Lüdtke R, Rutten ALB. The conclusions on the effectiveness of homeopathy highly depend on the set of analyzed trials. J Clin Epidemiol. 2008;61:1197-204. https://doi.org/10.1016/j.jclin epi.2008.06.015.

12. Majewsky V, Scherr C, Schneider C, Arlt SP, Baumgartner S. Reproducibility of the effects of homeopathically potentised
Argentum nitricum on the growth of Lemna gibba L. in a randomised and blinded bioassay. Homeopathy. 2017;106:145-54. https://doi.org/10.1016/j.homp.2017.04.001.

13. Amaya-Amaya M, Gerard K, Ryan M. Discrete choice experiments in a nutshell. In: Bateman IJ, Ryan M, Gerard K, AmayaAmaya M, editors. Using discrete choice experiments to value health and health care. Dordrecht: Springer; 2008. p. 13-46.

14. Lancaster KJ. New approach to consumer theory. J Polit Econ. 1966;74:132-57.

15. McFadden D. Conditional logit analysis of qualitative choice behavior. In: Zarembka P, editor. Frontiers in econometrics. New York: Academic; 1974. p. 105-42.

16. Chen L-C, Cheng L-J, Zhang Y, He X, Knaggs RD. Acupuncture or low frequency infrared treatment for low back pain in Chinese patients: a discrete choice experiment. PLoS One. 2015;10(5):e0126912. https://doi.org/10.1371/journal.pone.01269 12.

17. Ratcliffe J. Assessing patients' preferences for characteristics associated with homeopathic and conventional treatment of asthma: a conjoint analysis study. Thorax. 2002;57:503-8. https://doi. org/10.1136/thorax.57.6.503.

18. Vagias WM. Likert-type scale response anchors. Clemson, USA: Clemson University; 2006. https://www.sawtoothsoftware.com/ support/knowledge-base/design-and-methodology-issues/1444likert-scale-response-anchors. Accessed 25 July 2016.

19. Kassenärztliche Bundesvereinigung. Vertrag zur Versorgung mit klassischer Homöopathie gemäß § 73 c SGB V. http://www.kvhh. net/media/public/db/media/1/2012/01/396/homoeopathie_ikk_ lesefassung_idf_2.nachtrag_1.04.pdf. Accessed 3 Aug 2016.

20. Kassenärztliche Bundesvereinigung. Einheitlicher Bewertungsmaßstab (EBM). http://www.kbv.de/tools/ebm/. Accessed 4 Aug 2016.

21. Kuhfeld WF, editor. Marketing research methods in SAS: experimental design, choice, conjoint, and graphical techniques. Cary: SAS Institute Inc.; 2010.

22. Kuhfeld WF. Experimental Design: Efficiency, Coding, and Choice Designs. In: Kuhfeld, editor. Marketing research methods in SAS: experimental design, choice, conjoint, and graphical techniques. Cary: SAS Institute Inc.; 2010. pp. 53-241.

23. Orme BK. Sample Size Issues for Conjoint Analysis. In: Orme BK, editor. Getting started with conjoint analysis: strategies for product design and pricing research. 2nd ed. Madison: Research; 2010. p. 57-66.

24. Hauber AB, González JM, Groothuis-Oudshoorn CG, Prior T, Marshall DA, Cunningham C, et al. Statistical methods for the analysis of discrete choice experiments: a report of the ISPOR conjoint analysis good research practices task force. Value Health. 2016;19:300-15. https://doi.org/10.1016/j.jval.2016.04.004.

25. Lin DY, Wei LJ. The robust inference for the cox proportional hazards model. J Am Stat Assoc. 1989;84:1074-8. https://doi. org/10.1080/01621459.1989.10478874.

26. Wickham H. ggplot2: elegant graphics for data analysis. Dordrecht: Springer; 2009.

27. Hauber AB, Arden NK, Mohamed AF, Johnson FR, Peloso PM, Watson DJ, et al. A discrete-choice experiment of United Kingdom patients' willingness to risk adverse events for improved function and pain control in osteoarthritis. Osteoarthr Cartil. 2013;21:289-97. https://doi.org/10.1016/j.joca.2012.11.007.

28. Mühlbacher A, Bethge S. First and foremost battle the virus: eliciting patient preferences in antiviral therapy for hepatitis $\mathrm{C}$ using a discrete choice experiment. Value Health. 2016;19:776-87. https ://doi.org/10.1016/j.jval.2016.04.007.

29. Maha N, Shaw A. Academic doctors' views of complementary and alternative medicine (CAM) and its role within the NHS: an exploratory qualitative study. BMC Complement Altern Med. 2007;7:17. https://doi.org/10.1186/1472-6882-7-17. 
30. Antonovsky A. Health, stress, and coping. 1st ed. San Francisco: Jossey-Bass; 1991.

31. Johnson FR, Mohamed AF, Ozdemir S, Marshall DA, Phillips KA. How does cost matter in health-care discrete-choice experiments? Health Econ. 2011;20:323-30. https://doi.org/10.1002/hec.1591.

32. Ostermann J, Brown DS, de Bekker-Grob EW, Mühlbacher AC, Reed SD. Preferences for health interventions: improving uptake, adherence, and efficiency. Patient. 2017;10:511-4. https://doi. org/10.1007/s40271-017-0251-y.

33. Alemu MH, Mørkbak MR, Olsen SB, Jensen CL. Attending to the reasons for attribute non-attendance in choice experiments. Environ Resour Econ. 2013;54:333-59. https://doi.org/10.1007/ s10640-012-9597-8.

34. Sawtooth Software Inc., editor. The CBC system for choice-based conjoint analysis. Washington: Sawtooth Software, Inc.; 2017. https://www.sawtoothsoftware.com/support/technical-papers/cbcrelated-papers/cbc-technical-paper-2013. Accessed 20 Feb 2018.

35. Mühlbacher A, Bethge S, Tockhorn A. Präferenzmessung im Gesundheitswesen: grundlagen von Discrete-Choice-Experimenten. Gesundh ökon Qual manag. 2013;18:159-72. https:// doi.org/10.1055/s-0032-1330500.

36. Carlsson F, Kataria M, Lampi E. Dealing with ignored attributes in choice experiments on valuation of sweden's environmental quality objectives. Environ Resour Econ. 2010;47:65-89. https:// doi.org/10.1007/s10640-010-9365-6.

37. Bölter L, Sadler A, Mühlbacher A. Attribute non-attendance in discrete-choice-experimenten. Gesundh ökon Qual manag. 2017;22:135-43. https://doi.org/10.1055/s-0042-117959.

38. Kemppainen LM, Kemppainen TT, Reippainen JA, Salmenniemi ST, Vuolanto PH. Use of complementary and alternative medicine in Europe: health-related and sociodemographic determinants. Scand J Public Health. 2018;46(4):448-55. https://doi. org/10.1177/1403494817733869.

39. Lancsar E, Louviere J. Deleting 'irrational' responses from discrete choice experiments: a case of investigating or imposing preferences? Health Econ. 2006;15:797-811. https://doi.org/10.1002/ hec. 1104.

40. Miguel FS, Ryan M, Amaya-Amaya M. 'Irrational' stated preferences: a quantitative and qualitative investigation. Health Econ. 2005;14:307-22. https://doi.org/10.1002/hec.912.

41. Ryan M, Bate A. Testing the assumptions of rationality, continuity and symmetry when applying discrete choice experiments in health care. Appl Econ Lett. 2001;8:59-63. https://doi. org/10.1080/135048501750041312.

42. Huppelschoten AG, Verkerk EW, Appleby J, Groenewoud H, Adang EMM, Nelen WLDM, Kremer JAM. The monetary value of patient-centred care: results from a discrete choice experiment in Dutch fertility care. Hum Reprod. 2014;29:1712-20. https:// doi.org/10.1093/humrep/deu122.

43. Streibelt M, Bethge M. Patientenpräferenzen bei der Ausgestaltung Integrierter Versorgungsprogramme: ein Discrete Choice Experiment. Gesundh ökon Qual manag. 2009;14:288-95. https ://doi.org/10.1055/s-0028-1109409.

44. Bien DR, Danner M, Vennedey V, Civello D, Evers SM, Hiligsmann M. Patients' preferences for outcome, process and cost attributes in cancer treatment: a systematic review of discrete choice experiments. Patient. 2017;10(5):553-65. https://doi. org/10.1007/s40271-017-0235-y. 